\title{
Acute Aortic Dissection: Update on Diagnosis and Application of Endovascular Therapy of Emergency
}

\author{
Senival Alves de Oliveira1; Edlana Rebouças Veloso Guimarães ${ }^{1}$; Arnaldo Costa de Medeiros Junior ${ }^{1}$; Jéssica \\ Siebra Macário de Brito; ${ }^{1}$ Aline Vasconcelos de Carvalho1; Letícia Araújo Costa-Uchôa1; Irami Araújo-Neto ${ }^{1}$; \\ Amália Cinthia Menezes Rêgo²; Irami Araújo Filho ${ }^{2 *}$ \\ ${ }^{1}$ Undergraduate medical student, Potiguar University - Laureate International Universities - Natal, Rio Grande do Norte, South America \\ ${ }^{2}$ Full Professor of the Department of Surgery, PhD in Health Sciences. Potiguar University - Laureate International Universities, Natal, Rio Grande do \\ Norte, South America
}

Submission: February 28, 2017; Published: March 23, 2017

*Corresponding author: Irami Araújo Filho, Full Professor of the Department of Surgery, PhD in Health Sciences. Potiguar University - Laureate International Universities, Natal, Rio Grande do Norte, Brazil, South America, Tel: + 55 (84) 98876-0206 / 3342-5027; Fax: + 55 (84) 3342-5079; E-mail: irami.filho@uol.com.br / irami.filho@gmail.com

\begin{abstract}
Acute aortic syndrome (AAS) describes emergency aortic diseases. In 80\% of patients, the AAS presents itself as an Acute Dissection of Aorta (ADA). It's worth pointing out that the traumatic etiology of this condition, has great relevance regarding morbidity and mortality. This is fact that the Traumatic Thoracic Aortic Dissection (TTAD), usually occurs from a contuse injury, product of an abrupt deceleration, especially in men and individuals with overweight or obesity, which have a history of smoking and heart surgeries. Early diagnosis of ADA is indispensable, since patients who arrive alive at the hospital, have high probability of death in a short period of time if not treated properly, especially those who have been victims of some traumatic event earlier. In this context, the endovascular approach has become the treatment of choice for acute surgical emergencies involving the descending thoracic aorta. Moreover, it should be considered as a first-line option in the conduct of any emerging conditions that involve this region of the aorta. It is important to note that the longevity and durability of this technology throughout the life of young patients remains to be elucidated.
\end{abstract}

Keywords: Acute aortic syndrome; Acute aortic dissection; Dissection of aorta; Endovascular repair

Abbreviations: AAS: Acute aortic syndrome; ADA: Acute Dissection of Aorta; TTAD: Traumatic Thoracic Aortic Dissection; IH: Intramural Hematoma; PAU: Penetrating Atherosclerotic Ulcer; IRAD: International Registry of Aortic Dissection; CAT: Computed Angiotomography; TET: Transthoracic echocardiography and Transesophageal ETT and ETE; MRI: Magnetic Resonance Imaging; CT: Computed Tomography; CPB: Cardiopulmonary Bypass; EC: Extracorporeal Circulation

\section{Introduction}

Acute Aortic Syndrome (AAS) is a term used to describe emergency aortic disorders, with regard to its characteristics and challenges. Because of this, one can cite: acute aortic dissection (AAD), intramural hematoma (IH) and penetrating atherosclerotic ulcer (PAU). The incidence of this syndrome is three cases per 100,000 people per year. Of all patients who present with a SAA, $80 \%$ are AAD, $15 \% \mathrm{HI}$ and $5 \%$ corresponds to the PAU [1]. Most patients who arrive alive at the hospital, if they are not subjected to a systematic approach and conducive situation, have a high probability of death in a small time interval [2]. As AAS occurs through an injury to the wall of this artery due to a certain type of stress or even medial degeneration, it is essential to know the risk factors that can cause this fragility [3].
The conditions associated with the medial degeneration include Marfan syndrome, Loeys-Dietz syndrome, vascular Ehlers-Danlos syndrome, inflammatory diseases of the aorta, Turner syndrome, bicuspid aortic valve, familiar syndrome of thoracic aortic aneurysm and dissection [4]. The most common condition that increases the stress of wall is hypertension. Other conditions involved in the dissection include: history of trauma, weight lifting, pheochromocytoma, coarctation and cocaine [4].

Meet the clinical signs is essential, once, tied to Imaging tests, they become important allies to diagnose or rule out a leave according to the technology available inservice [5]. In addition, in a patient with hemodynamic stability studies, graduating from injury is essential to direct more productive and effective conduct. The image examinations for your 
time, besides being favorable for the diagnosis, can assist in choosing the best surgical technique. If there are no unfavorable anatomical changes, the choice of approach will depend on the patient's hemodynamic condition, availability of resources and professional skill in question [5-7].

From this reality, this article has as purpose, do a literature review on the acute aortic dissection, clarifying the main and latest methods of diagnostic and therapeutic approach. In addition, underscores the urgent need, the preparation of the team on admission of patients affected by this disease, so that it is possible to decrease the incidence of undiagnosed cases, optimizing the time between the initial approach and appropriate conduct [8].

\section{Methods}

This work was done from an electronic search in the databases PubMed, Scopus, Scielo and Embase Search Portal. We collected data from case reports, cohort studies and literary reviews, using the key words: acute aortic syndrome, acute aortic dissection, dissection of aorta, endovascular repair. The method presented the following guiding question: "what are the main results and scientific evidence identified in national and international bibliographical production of the last 26 years pertaining to diagnostic and therapeutic approach of acute aortic dissection?"

In the initial survey, the articles went through the evaluation of nine researchers (authors), in accordance with the following inclusion criteria: articles published in Portuguese, English or Spanish, to submit the combinations of the keywords selected, with publication date between 1989 and 2015 that were accessible. After the initial selection of material, were deleted the articles repeated in different databases and they focus on the aortic pathologies other mixed in question. Although picked by articles that cover effective updates in the treatment, the therapeutic failure was not used as a criterion for deletion, considering the particularity of the manifestations of each case. The final material featured 46 scientific articles.

\section{Results}

The AAD is a potentially fatal condition that requires rapid assessment and intervention. However, despite the great advances in imaging methods and non-invasive studies, the correct diagnosis is not always the rule, therefore the diagnosis errors often occur [9]. Approximately 30\% of cases are found in post-mortem exams [8]. Patients with this disease presents to the Emergency Department with a wide variety of symptoms, due to the involvement of multiple organ systems [10]. However, there are occasions when the medical history is insufficient to know the frame [10].

\section{Clinical Presentation}

The patient may complain of chest pain, pain in interescapular region, dyspnea and dysphagia [3]. The physical examination may show signs suggest chest trauma, such as the seatbelt sign, heart murmur, hematemesis, palpable depression or deformity of the sternum. As well: stridor, crepitation in chest wall, grinding noise on the precordium (Hamman signal), hematoma subclavian and femoral pulses decreased [3]. If the patient is hemodynamically unstable must be forwarded immediately to the operating room [11]. Stable patients can be investigated more precisely through Imaging tests.

\section{Diagnostic Methods}

The evolution of technology has resulted in highly sensitive diagnostic tools and specific, however, the widespread use of these diagnostic methods, results in an increase in the number of false positives. Such limitations should be considered in clinical decisions, and it is important that additional tests in patients hemodynamically stable [12]. The international registry of aortic dissection (IRAD) lists the computed angiotomography (ATC) as the first most common diagnostic test on suspicion of aortic dissection (about 61\%), followed by Transthoracic echocardiography and Transesophageal (ETT and ETE) (around $33 \%$ ), magnetic resonance imaging (MRI) (around 2\%), in addition to angiography corresponding to $4 \%$. This reflects their availability and accessibility of these modalities [13] (Figure 1).

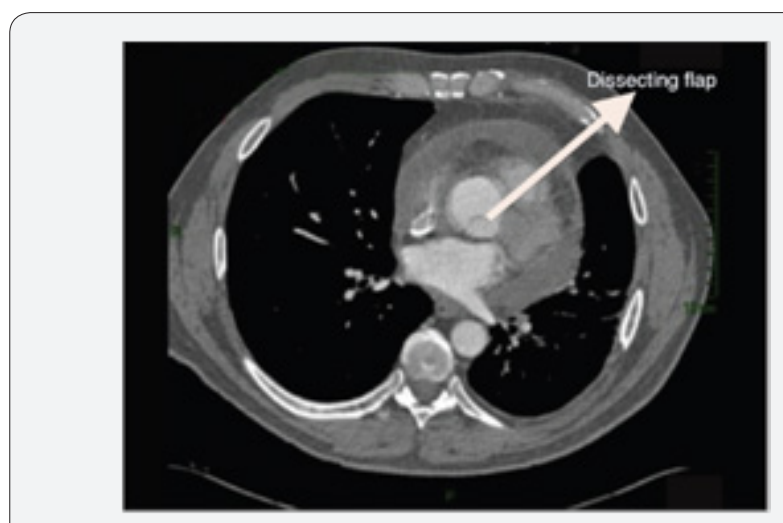

Figure 1: CT showing dissection in ascending portion of the thoracic aorta.

The chest $\mathrm{x}$-ray in supine anteroposterior position, can be useful, since in an initial assessment, despite having low sensitivity, shows signs that direct the diagnosis or the need for other tests [5]. These evidences are: widening of the mediastinum ( $>8 \mathrm{~cm}$ ); abnormal aortic contour; deletion of aortic button; orotracheal tube and trachea deviation to the right; source left bronchus depression; diversion of nasogastric tube to the right; extrapleural apical leakage; a density; fracture of the first and second ribs; obliteration of the space between the pulmonary artery and aorta; elevation and deflection to the right of the right main bronchus; hemothorax. The helical computed tomography (CT) of chestno cuts must be indicated after the fine interpretation of trauma mechanisms [3]. Is the most common initial examination because it is less invasive and allows quick diagnosis in emergency situations [14]. Is an excellent method 
for diagnosis to triage patients with suspected aortic injury, showing a sensitivity ranging from $93 \%$ to $100 \%$ and specificity of $87 \%$ to $100 \%[3,15,16]$ (Figure 2 ).

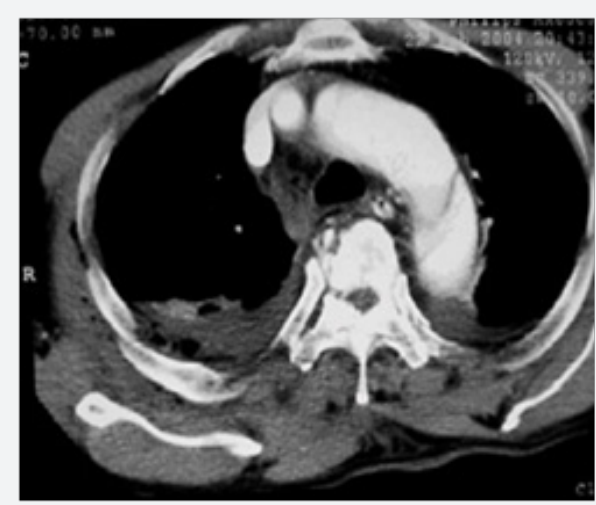

Figure 2: $\mathrm{CT}$ of the thorax evidencing filling failure in the posterior portion of the aortic arch and beginning of the descending. Bilateral hemothorax.

With this test, you can distinguish the mediastinal blood from other causes dilation of the mediastinum, in addition to show if there is intimate or laceration, hematoma, aortic pseudoaneurysm, periaortic rupture contained or active extravasation of IV contrast [11]. It's worth pointing out that the primary diagnostic criterion is the demonstration of two lumens full of contrast separated by an intimate tab [15]. The minimally invasive transesophageal echocardiography, is widely available, secure, and can be accomplished quickly and easily on the edge of the bed or in the operating room before the operation. These advantages make this ideal for use in most patients with aortic dissections, including those relatively unstable. The examination can be carried out immediately after the patient to come to the Emergency Department. Their sensitivity ranges from 95\% to $98 \%$ and specificity of $63 \%$ to $96 \%[17,18]$.

The most important discovery in the diagnosis of aortic dissection, which can be seen in this survey, is the presence of a border rippling intimal within the lumen of the aorta, which differentiates a false lumen light real [19]. The arteriography was used for many years as the mode of choice to demonstrate the aortic dissection. Is an effective procedure to demonstrate the direct signals of dissection, the flap of the intimate and blood flow in the true and false lumens [19]. Erbel et al. [17] reported $88 \%$ sensitivity and specificity of $94 \%$ for this examination in the diagnosis of aortic dissection. However, for being an invasive method, became a secondary diagnosis mode.

Magnetic resonance imaging (MRI)is a non-invasive research, providing an excellent analysis of the valvar pathologies, and aortic coronary involvement. Although it is the most accurate, sensitive and specific between the four modes of diagnosis [16], your use is limited in emergency situations, in patients hemodynamically unstable, as well as in patients with Implantable devices. That way, she will eventually cede space to the computed angiotomography methods and echocardiography in emergency cases [20]. Has a sensitivity around 95\% and specificity of $100 \%$ [21]. The advantage of MRI over CT, is your ability to provide functional information such as valve failure and left ventricular dysfunction [19] (Figure 3).

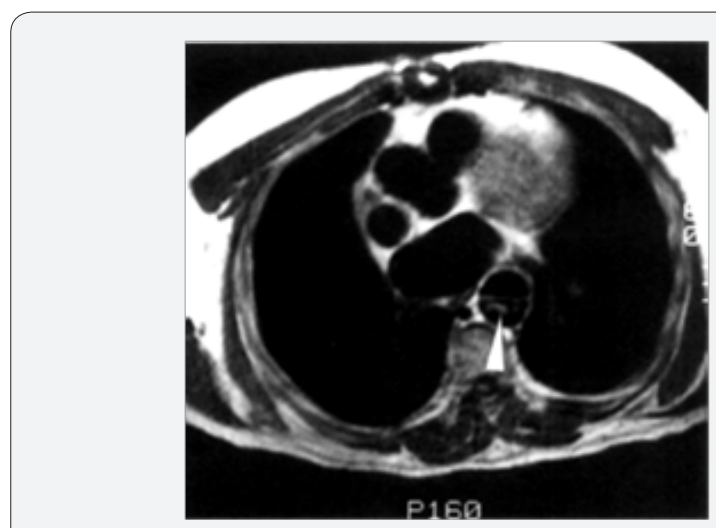

Figure 3: MRI: revealing descending thoracic aorta dissection; Intraluminal sign (arrow) in false lumen, representing a slow and turbulent blood flow.

The use of quantitative tests of D-Dimer serum, have been proposed as a strategy to ward offaortic dissection [22]. Proponents of this approach suggest that the blood in the false light, activates the coagulation cascade by generating fibrin degradation products. These are detected by modern D-Dimer assays with high sensitivity. Unfortunately, the work has demonstrated high false negative rate. In one study, D-Dimer presented false negatives in 9 of 113 confirmed cases of aortic dissection [23].

The proposed explanation for D-Dimer tests false negatives, is the occurrence of an anatomical variation of aortic dissection, whose thrombosed lumen, does not communicate with the circulating blood, isolating the clot detection by serum tests [23]. In addition, there is no evidence that D-Dimer can be incorporated into a strategy of risk stratification, which would allow the sensitive clinical enough to exclude aortic dissection, without significantly increasing the number of patients who receive advanced imaging tests. Given the experience of D-Dimer testing to rule out pulmonary embolism-which increased the number of advanced studies of image without increasing the number of diagnoses of pulmonary embolism [24]. A comprehensive approach to answer for false negatives and false positives, should be validated before this exam to be used routinely in the diagnosis of aortic dissection [24].

\section{Clinical Approach}

The initial treatment has as main objective to reduce the shear stress in the wall of the aorta, through the control of blood pressure. The first line of treatment are beta blockers intravenously (labetalol or propranolol). Those with contraindication for this drug class (asthma) [25], is preferable to the use of intravenous calcium channel blocker (verapamil or diltiazem). Because of this, it is necessary to get a systolic blood pressure that oscillates between 100 and $120 \mathrm{mmHg}$, as 
well as a range of heart rate between 60 and $80 \mathrm{bpm}$. Besides, we recommend the use of an opioid analgesic (morphine), to reduce sympathetic discharge produced by catecholamines. These are generated by pain, due to the hypertension and tachycardia [26].

It is worth mentioning that the initial conduct in stable patients depends on the degree of the injury established after CT $[5,6]$. There are four ranks: type I-intimate layer, without blood extravasation; type II - intramural hematoma; type III pseudoaneurysm; type IV - break free/periaortic hematoma. In milder cases (type I), opts for the use of beta blockers for fast action and short half-life, decreasing blood pressure and keeping your heart rate below $100 \mathrm{bpm}$, if they are contraindicating, a calcium channel blocker or associated with intravenous nitroglycerine if there is the effect objectified. In addition, it is necessary to perform Imaging exams serials to accompany the evolution of the injury. In more severe lesions (types II, III and IV), as well as volume replacement and blood pressure control, surgical repair is required for open or endovascular technique $[5,6]$.

\section{Surgical Approach}

Regarding surgical techniques, we can cite the open technique based on a left thoracotomy in cases of injury of the descending aorta or sternotomy in patients with injury of the ascending aorta for primary repair of the aorta or the replacement of the affected segment by a graft or graft [7]. In the descending aorta lesions, should be made the establishment of diversion of blood flow through centrifugal pumps and cannulation of the left atrium and left common femoral artery, as well as systemic heparinization. This technique is preferable in patients with unfavorable anatomy [7]. It's worth pointing out that many patients do not survive the initial event, consequently does not undergo a repair attempt.

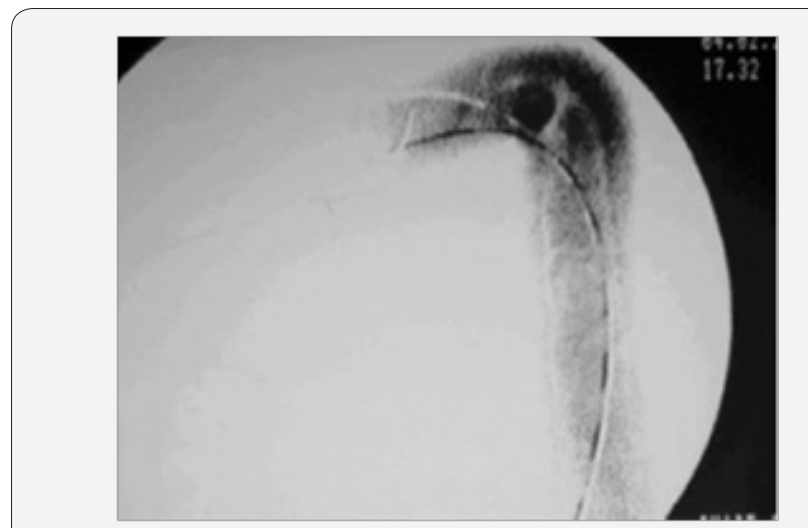

Figure 4: Aortography - Before endoprosthesis implantation. Note the graduated catheter and filling faults in the lumina of the aorta.

Endovascular thoracic aortic repair (TEVAR), refers to the minimally invasive approach, which involves placing a stent graft in thoracic aorta or ring, possessing ample indications. The technique involves inserting modular grafts through the dissection of iliac or femoral arteries to thoracic aorta excluding vessel damage [7] (Figures 4 \& 5). In the case of femoral arteries, after dissection of the right femoral puncture of femoral artery left there for the introduction of catheter, where there is the diameter of the aorta and if intralaminar defects are excluded, when inserted into the stent. Is recommended in victims with favorable anatomy, and has a more comfortable postoperative period and brief [7].

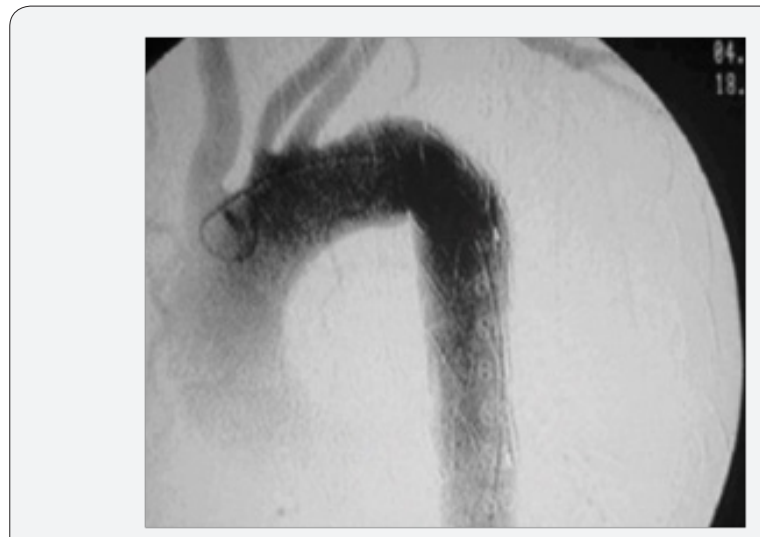

Figure 5: Aortography - After endoprosthesis implantation.

A series of studies, has suggested various subgroups of highrisk patients without complications, which can benefit from early TEVAR. The specific predictors of early or late adverse events have been identified in multiple studies, and include: an aortic diameter of $4.0 \mathrm{~cm}$ home, with a false light patent [2729], an initial diameter of $22 \mathrm{~mm}$ light on proximal descending aorta [30], refractory/recurrent pain or hypertension [31] or intramural hematoma with a penetrating atherosclerotic ulcer development in the proximal descending aorta [27,29]. About the disasters involving the descending thoracic aorta, the management have been particularly difficult for surgeons. The open surgical correction in these cases, is the gold standard. However, is associated with significant mortality and morbidity. This makes this procedure, one of the most risky and difficult to be carried out by vascular surgeons [32].

The widespread application of endovascular repair, for the treatment of acute surgical emergencies involving the descending portion of the aorta, resulted in a dramatic decrease of both the operative mortality as post procedure morbidity [33]. The open repair for traumatic rupture of the aorta, is associated with an operative mortality of up to $28 \%$ and $16 \%$ rate of paraplegia [33]. While a systematic review of literature on endovascular therapy, reveals an overall rate of $9 \%$ and a mortality rate of $3 \%$ of the paraplegia analyze 7768 patients undergoing the procedure in effect of traumatic dissection of aorta [34]. Recently published guidelines for the Society for Vascular Surgery, with practical guidelines that suggest that endovascular procedure must be standard therapy for the treatment of traumatic rupture of the thoracic aorta [35]. Thus, the endovascular approach has become the treatment of choice for acute surgical emergencies, involving the descending thoracic aorta. Moreover, it should be considered as a first-line option in the conduct of any emerging conditions that involve this region of the aorta [36]. 
Endovascular repair brings advantages and limitations. Among the advantages described, include: avoid the thoracotomy, decrease the incidence of complications less painful, faster recovery, shorter stay in intensive care and in hospital, an alternative for high-risk patients, less postoperative complications, useful in emergency situations and speed and agility of treatment [37]. Among the limitations found: institutional and political constraints, limited availability and accessibility, unavailable commercially in some countries, the appropriate requirement of vascular anatomy, limited number of qualified operators, lack of appropriate follow-up and palliative care in most cases [37].

However, endovascular correction is not without risks. This procedure is associated with a small but measurable rates of stroke ( $2 \%$ of cases), spinal cord ischemia ( $0.9 \%$ of cases), reported in the trials and meta-analysis that investigated this type of therapy [38-41]. In addition, endovascular procedures are associated with higher rates of complications related to the device. They are expensive and require an extended image tracking. In addition, the longevity and durability of this technology throughout the life of young patients remains to be elucidated [39].

In the first month, post-operative angiography should be performed by a CT scan, followed by study of image in six months, and then annually. TEVAR in patients with non-optimal anatomy for the procedure, requires more rigorous follow-up. The realization of the computed tomography without contrast allows the measurement of the diameter of the bag and is enough in most cases to document effective aneurysm exclusion [42]. Magnetic resonance angiography is an alternative, although it is of limited applicability in patients with significant renal dysfunction [42]. A secondary is relatively common aortic intervention after the endovascular repair $[43,44]$.

\section{Discussion}

According to the American Heart Association guidelines on the management of thoracic aortic diseases, we have that the acute aortic dissection can be categorized in a patient of high, medium and low risk according to clinical presentation [45]. In cases of high risk or intermediate probability, one must quickly make the injury screening with imaging to visualize the aorta. Obtaining a negative result, opts for another investigation. The cardiac ultrasound is offered by AHA as secondary technique more common [20]. It's worth pointing out that a CT must be part of the pre-surgical routine, as well as being performed by a trained and highly experienced cardiologist or cardiac anesthesiologist. This procedure is required in all patients with suspected acute aortic dissection type A [10].

The work performed by Tiwari et al. discusses several puncture techniques that were proposed in the establishment of the cardiopulmonary bypass (CPB) for the surgery of acute type A aortic dissection. Despite the concern with the fragility of the vases, and distal embolization during ascending aortic cannulation of a dissected aorta, there were promising results, with a lower mortality rate and lower incidence of poor perfusion. However, it was observed a higher rate of stroke. A total of seven studies evaluated the use of direct aortic cannulation for the establishment of the extracorporeal circulation (EC). They have shown and stroke mortality rates from $0 \%$ to $15 \%$ and $3.8 \%$ and $21 \%$, respectively. The direct cannulation of the true light is an emerging method for quick and easy establishment of EC [46].

Although the femoral artery puncture is the default option in many centers, there is a higher rate of mortality of stroke and other complications, including cerebral embolization bad organ perfusion retrograde perfusion of the false light. In this work, five of the 14 studies analyzed, reported benefits of axillary artery cannulation (or subclavian). In a total of 1829 patients evaluated in these studies, 1068 patients demonstrated a significantly lower rate of complications with the axillary artery cannulation in comparison with the femoral artery [46].

Some large studies have shown that the femoral artery cannulation have high rates of stroke and mortality ranging from $6.5 \%$ to $40 \%$, and $3 \%$ to $17 \%$, respectively. Meanwhile, and mortality rates of stroke ranged from $3 \%$ to $8.6 \%$ and $1.75 \%$ and $4 \%$, respectively, in the axillary artery cannulation procedure [45]. This new strategy emerges as a more efficient method for the EC, providing unilateral continuous blood flow without interruption. Although need more time for your accomplishment, the axillary artery with lateral graft, proved to be safe and straightforward, with less local and systemic complications, lower mortality and reduction of neurological complications [46]. It is important to note that in the case of hemodynamic stability, and the patient in question is subject to a traumatic brain injury or multiple severe injuries in other systems coexisting, but there is no indication of impending rupture of the aorta, aortic, pneumothorax massive thrombus or pseudoaneurysm, thoracic aortic repair chosen must be conservative (pharmacological control of arterial pressure) to stabilization of other injuries or comorbidities by decreasing the amount of anesthetic held, as well as the surgical risk [5,6].

\section{Conclusion}

Most of the patients are victims of a ruptured aorta after an accident, die immediately. However, the small portion survivor, has about $24 \mathrm{~h}$ for that light to rupture. As the clinical findings are nonspecific and poor, shows need for greater professional skill, regarding the efficient diagnosis, rapid and appropriate treatment to approach this serious pathology. It is important to point out that when we are facing a situation of hemodynamic stability and the first-rate research results are conflicting, it is necessary to refer the patient to a high level of investigative rigor before surgical intervention. An alternative to conventional surgical treatment is the use of endoprothesis, reserved for patients properly selected. In addition, it is essential the image 
exams serials, as well as medical follow-up according to age, comorbidities and patient kidney function.

\section{References}

1. Evangelista M (2004) Historia natural y tratamiento del síndrome aórtico agudo. Rev Esp Cardiol 57(7): 667-679.

2. Martin C, Thony F, Rodiere M, Bouzat P, Lavagne P, et al. (2017) Longterm results following emergency stent graft repair for traumatic rupture of the aortic isthmus. Eur J Cardiothorac Surg.

3. Pape HC, Remmers D, Rice J, Ebisch M, Krettek C, et al. (2000) Appraisal of early evaluation of blunt chest trauma: development of a standardized scoring system for initial clinical decision making. J Trauma 49(3): 496-504.

4. Goldfinger JZ, Halperin JL, Marin ML, Stewart AS et al. (2014) Thoracic Aortic Aneurysm and Dissection. Journal of the American College of Cardiology 64: 1725-1739.

5. MANNING, Warren J III, Emile $R$ Mohler EIDT, John F (2013) Management of aortic dissection.

6. Bernard Y, Zimmermann H, Chocron S, Litzler JF, Kastler B, et al. (2001) False lumen patency as a predictor of late outcome in aortic dissection. Am J Cardiol 87(12): 1378-1382.

7. Harris DG, Rabin J, Starnes BW, Khoynezhad A, Conway RG, et al. (2016) Evolution of lesion-specific management of blunt thoracic aortic injury. J Vasc Surg 64(2): 500-505.

8. Spittell PC, Spittell JA Jr, Joyce JW, Tajik AJ, Edwards WD, et al. (1993) Clinical features and differential diagnosis of aortic dissection: Experience with 236 cases (1980 through 1990). Mayo Clin Proc 68(7): 642651.

9. Hansen MS, Nogareda GJ, Hutchison SJ (2007) Frequency of and inappropriatetreatment of misdiagnosis of acute aortic dissection. Am J Cardiol 99(6): 852-856.

10. Kanwar Aditya Baloria, Achal Dhir, Biju Pillai, Nandini Selot. Aortic dissection: To be or not to be? Annals of Cardiac Anaesthesia 16(2): 126-128.

11. Bottet B, Bouchard F, Peillon C, Baste JM (2016) When and how should we manage thoracic aortic injuries in the modern era? Interact Cardiovasc Thorac Surg 23(6): 970-975.

12. Balooria KA, Dhir A, Pillai B, Selot N (2013) Aortic dissection: To be or not to be? Annals of Cardiac Anaesthesia 16: 126-128.

13. Nienaber CA, Eagle KA (2003) Aortic dissection: New frontiers in diagnosis and management: Part I: From etiology to diagnostic strategies. Circulation 108: 628-635.

14. Hagan PG, Nienaber CA, Isselbacher EM, Bruckman D, Karavite DJ, et al (2000) The International Registry of Acute Aortic Dissection (IRAD): new insights into an old disease. JAMA 283(7): 897-903.

15. Cigarroa JE, Isselbacher EM, DeSanctis RW, Eagle KA (1993) Diagnostic imaging in the evaluation of suspected aortic dissection. Old standards and new directions. N Engl J Med 328(1): 35-43.

16. Nienaber CA, von Kodolitsch Y, Nicolas V, Siglow V, Piepho A, et al. (1993) The diagnosis of thoracic aortic dissection by noninvasive imaging procedures. N Engl J Med 328(1): 1-9.

17. Erbel R, Engberding R, Daniel W, Roelandt J, Visser C, et al. (1989) Echocardiography in diagnosis of aortic dissection. Lancet 1: 457-461.

18. Nathan DP, Shalhub S, Tang GL, Sweet MP, Verrier ED, et al. (2015) Outcomes after stent graft therapy for dissection-related aneurysmal degeneration in the descending thoracic aorta. J Vasc Surg 61(5): 1200-1206.
19. Halefoğlu AM (2007) Emergency diagnosis of acute aortic dissection using magnetic resonance imaging. Ulus Travma Acil Cerrahi Derg 13(2): 106-114.

20. Nienaber CA, Kische S, Ince H, Fattori R (2011) Thoracic endovascular aneurysm repair for complicated type B aortic dissection. J Vasc Surg 54(5): 1529-1533.

21. Faure EM, Canaud L, Agostini C, Shaub R, Böge G, et al. (2014) Reintervention after thoracic endovascular aortic repair of complicated aortic dissection. J Vasc Surg 59(2): 327-333.

22. Suzuki T, Distante A, Zizza A, Trimarchi S, Villani M, et al. (2009) Diagnosis of acute aortic dissection by d-dimer: The international registry of acute aortic dis-section substudy on biomarkers (irad-bio) experience. Circulation 119(20): 2702-2707.

23. Hazui H, Nishimoto M, Hoshiga M, Negoro N, Muraoka H, et al. (2006) Young adult patients with short dissection length and thrombosed false lumen without ulcer-like projections are liable to have falsenegative results of ddimer testing for acute aortic dissection based on a study of 113 cases. Circ J 70(12): 1598-1601.

24. Kabrhel C, Matts C, McNamara M, Katz J, Ptak T (2006) A highly sensitive ELISA d-dimer increases testing but not diagnosis of pulmo-nary embolism. Acad Emerg Med 13(5): 519-524.

25. Piffaretti G, Mariscalco G, Tozzi M, Bruno VD, Sala A, et al. (2010) Acute iatrogenic type A aortic dissection following thoracic aortic endografting. J Vasc Surg 51(4):993-999.

26. Nienaber C, Powell J (2012) Management of acute aortic syndromes. Eur Heart J 33: 26-35.

27. Winnerkvist A, Lockowandt U, Rasmussen E, Radegran K (2006) A prospective study of medically treated acute type B aortic dissection. Eur J Vasc Endovasc Surg 32(4): 349-355.

28. Marui A, Mochizuki T, Koyama T, Mitsui N (2007) Degree of fusiform dilatation of the proximal descending aorta in type B acute aortic dissection can predict late aortic events. J Thorac Cardiovasc Surg 134(5): 1163-1170.

29. Kitai T, Kaji S, Yamamuro A, Tani T, Kinoshita M, et al. (2010) Impact of new development of ulcer-like projection on clinical outcomes in patients with type B aortic dissection with closed and thrombosed false lumen. Circulation 122(11): S74-80.

30. Song JM, Kim SD, Kim JH, Kim MJ, Kang DH, et al. (2007) Long-term predictors of descending aorta aneurysmal change in patients with aortic dissection. J Am Coll Cardiol 50(8): 799-804.

31. Trimarchi S, Eagle KA, Nienaber CA, Pyeritz RE, Jonker FH, Suzuki T, et al. (2010) Importance of refractory pain and hypertension in acute type B aortic dissection: insights from the International Registry of Acute Aortic Dissection (IRAD). Circulation 122(13): 1283-1289.

32. Lee WA, Matsumura JS, Mitchell RS, Farber MA, Greenberg RK, et al. (2011) Endovascular repair of traumatic thoracic aortic injury: clinical practice guidelines of the Society for Vascular Surgery. J Vasc Surg 53(1): 187-192.

33. Demetriades D, Velmahos GC, Scalea TM, Jurkovich GJ, Karmy-Jones $\mathrm{R}$, et al. (2008) Operative repair or endovascular stent graft in blunt traumatic thoracic aortic injuries: results of an American Association for the Surgery of Trauma Multicenter Study. J Trauma 64(3): 561-570.

34. Murad MH, Rizvi AZ, Malgor R, Carney J, Alkatib AA, et al. (2011) Comparative effectiveness of the treatments for thoracic aortic transection. J Vasc Surg 53(1): 193-199.

35. Lee WA, Matsumura JS, Mitchell RS, Farber MA, Greenberg RK, et al. (2011) Endovascular repair of traumatic thoracic aortic injury: clinical practice guidelines of the Society for Vascular Surgery. J Vasc Surg 53(1): 187-192 
36. Mitchell ME, Rushton FW Jr, Boland AB, Byrd TC, Baldwin ZK (2011) Emergency procedures on the descending thoracic aorta in the endovascular era. J Vasc Surg 54(5): 1298-1302.

37. Soares JS (2009) Reparo Endovascular de Aneurisma de Aorta Torácica: experiência de 16 casos. Rev Socerj. Rio de Janeiro 1(22): 31-35.

38. Xenos ES, Abedi NN, Davenport DL, Minion DJ, Hamdallah O, et al. (2008) Meta-analysis of endovascular vs open repair for traumatic descending thoracic aortic rupture. J Vasc Surg 48(5): 1343-1351.

39. Azizzadeh A, Charlton-Ouw KM, Chen Z, Rahbar MH, Estrera AL, et al. (2013) An outcome analysis of endovascular versus open repair of blunt traumatic aortic injuries. J Vasc Surg 57(1): 108-114.

40. Demetriades D, Velmahos GC, Scalea TM, Jurkovich GJ, Karmy-Jones $\mathrm{R}$, et al. (2008) Operative repair or endovascular stent graft in blunt traumatic thoracic aortic injuries: results of an American Association for the Surgery of Trauma Multicenter Study. J Trauma 64(3): 561-570.

41. Tang GL, Tehrani HY, Usman A, Katariya K, Otero C, et al. (2008) Reduced mortality, paraplegia, and stroke with stent graft repair of blunt aortic transections: a modern meta-analysis. J Vasc Surg 47(3) 671-675.

42. Rylski B, Blanke P, Siepe M, Kari FA, Euringer W, et al. (2013) Results of high-risk endovascular procedures in patients with non-dissected thoracic aortic pathology: intermediate outcomes. Eur J Cardiothorac Surg 44(1): 156-162.
43. Scali ST, Beck AW, Butler K, Feezor RJ, Martin TD, et al. (2014) Pathology-specific secondary aortic interventions after thoracic endovascular aortic repair. J Vasc Surg 59(3): 599-607.

44. Verzini F, Loschi D, De Rango P, Ferrer C, Simonte G, et al. (2014) Current results of total endovascular repair of thoracoabdominal aortic aneurysms. J Cardiovasc Surg (Torino) 55(1): 9-19.

45. Hiratzka LF, Bakris GL, Beckman JA, Bersin RM, Carr VF, Casey DE Jr, et al. (2010) 2010 ACCF/AHA/AATS/ACR/ASA/SCA/SCAI/SIR/STS/ SVM Guidelines for the diagnosis and management of patients with thoracic aortic disease. A report of the American college of cardiology foundation/American heart association task force on practice guidelines, American association for thoracic surgery, American college of radiology, American stroke association, society of cardiovascular anesthesiologists, society for cardiovascular angiography and interventions, society of interventional radiology, society of thoracic surgeons, and society for vascular medicine. Circulation 121(13): 266369 .

46. Tiwari KK, Murzi M, Bevilacqua S, Glauber M (2010) Which cannulation (ascending aortic cannulation or peripheral arterial cannulation) is better for acute type A aortic dissection surgery? Interact Cardiovasc Thorac Surg 10(5): 797-802.

\section{Your next submission with Juniper Publishers will reach you the below assets}

- Quality Editorial service

- Swift Peer Review

- Reprints availability

- E-prints Service

- Manuscript Podcast for convenient understanding

- Global attainment for your research

- Manuscript accessibility in different formats

( Pdf, E-pub, Full Text, Audio)

- Unceasing customer service

Track the below URL for one-step submission https://juniperpublishers.com/online-submission.php 